\title{
Incidence and prevalence of gout in Western Sweden
}

\author{
Mats Dehlin ${ }^{1 *} \mathbb{D}$, Panagiota Drivelegka', Valgerdur Sigurdardottir ${ }^{2}$, Anna Svärd $^{2}$ and Lennart T. H. Jacobsson ${ }^{1}$
}

\begin{abstract}
Background: The aim of the present study was to describe prevalence and trends in the incidence of gout and patterns of urate-lowering treatment (ULT) in the Western Swedish Health Care Region (WSHCR) from 2002 to 2012.

Methods: We used regional and national healthcare registers to estimate the prevalence and incidence of gout in 2012, and trends in incidence for each calendar year from 2005 to 2012. We also investigated the pattern of ULT for gout using the Swedish Prescribed Drug Register.

Results: In 2012, in the population aged 20 years and above, the prevalence of gout was $1.8 \%$ (95\% confidence interval (CI) 1.77 to 1.82) and the incidence was 190 cases (95\% Cl 180 to 200) per 100,000 person-years. Applying more strict definitions for a gout case rendered a prevalence of $1.36 \%(95 \% \mathrm{Cl} 1.34$ to 1.38 ) and 0.5 (95 \% Cl 0.49 to 0.51$)$ per 100,000 person-years, respectively. The incidence of gout increased steadily and significantly from 2005 to 2012, with an almost $50 \%$ increase in the total population. There was no significant difference in the prevalence of gout in rural compared to urban areas. ULT was dispensed to only $42 \%$ of patients with gout in 2012 who had ever been diagnosed with gout during the preceding 10-year period.
\end{abstract}

Conclusions: Gout is the most common arthritic disease in WSHCR, Sweden, and has increased substantially over the last decade, with only a minority of prevalent cases in 2012 receiving ULT.

Keywords: Gout, Prevalence, Incidence, Urate lowering treatment

\section{Background}

Gout is the most common form of inflammatory arthritis with a prevalence range of $1-4 \%$ in North America and Western Europe [1-5]. Different approaches to identification of gout cases (diagnostic definitions) have been used in these studies, including International Classification of Diseases (ICD) codes in diagnosis registers and administrative claims databases $[4,6]$, ICD codes combined with hyperuricemia or gout treatment $[1,7]$, classification criteria [3], self-reported gout in home interviews [2], and gout diagnosis questionnaire performed by telephone interview $[5,8]$. Recurrent episodes of pronounced acute inflammation due to deposition of monosodium urate crystals result in pain and frequently subsequent chronic arthritis with large disability for the individual and great costs for society. Gout is also closely

\footnotetext{
*Correspondence: mats.dehlin@vgregion.se

${ }^{1}$ Department of Rheumatology and Inflammation Research, Institute of Medicine, Sahlgrenska Academy, University of Gothenburg, Gothenburg, Sweden

Full list of author information is available at the end of the article
}

associated with a number of comorbidities, including cardiovascular morbidity, and has been shown to be associated with an increased mortality $[9,10]$.

Several studies suggest an increasing incidence and prevalence of gout, for example in the UK and North America [4], which is not solely explained by longer survival of the general population. There are large geographical variations in prevalence which probably reflects cultural and genetic differences between populations [11]. This stresses the need for regional and national data. There is an almost complete lack of reports regarding prevalence and no studies on incidence of gout in Sweden or other Nordic countries [12-15]. Studies from the UK [1] and Italy [16] suggest variations in prevalence within countries, possibly reflecting differences in lifestyle. The present study addresses these issues within the western part of Sweden, an area which is representative of the country as a whole in terms of demographics, socioeconomic factors, and healthcare consumption $[17,18]$. 
The aims of the present study were to assess in the Western Swedish Health Care Region (WSHCR): 1) the incidence and prevalence of gout in 2012;2) possible differences in prevalence in rural and urban areas; 3 ) the proportion of patients having received a diagnosis of gout receiving urate-lowering treatment (ULT); and 4) trends in incidence of gout from 2005 through 2012.

\section{Methods}

\section{Study design}

This is a population-based study of incidence and prevalence rates using national healthcare registers.

\section{Setting and study population}

All inhabitants aged 20 years and above in the WSHCR from 1 January 2002 to 31 December, approximately $20 \%$ of the total population of Sweden, were included.

\section{Data sources}

The Western Swedish Health Care Register (VEGA) was used to identify cases with gout and to determine the occurrence of diagnosed comorbidities. This register contains information about all healthcare contacts at inpatient and outpatient secondary clinics, as well as at primary care clinics. The register contains the date of contact and both primary and auxiliary diagnoses given by the treating physician according to the Swedish version of the ICD. Since 1997 the $10^{\text {th }}$ version of ICD (ICD-10) has been used in Sweden.

The Swedish Prescribed Drug Register [19] contains information about all prescribed drugs dispensed by Swedish pharmacies since July 2005. This register was used to determine dispensation of ULT as well as use of diuretics during 2012, using the appropriate Anatomical Therapeutic Chemical Classification System (ATC codes) (for more information see Additional file 1: Table S1).

Demographic data were obtained from Statistics Sweden [18], which holds data on immigration, emigration, and residency, as well as data on socio-economic factors (e.g., marital status and level of formal education) for all persons residing in Sweden.

\section{Case definition of gout}

Gout was defined as having been given an ICD coded diagnosis of gout (M10 or M14) at a healthcare visit to a physician from 1 January 2002 through 31 December 2012. Gout was defined by three definitions: 1) liberal case definition requiring $\geq 1$ visit in any care setting with a primary or auxiliary diagnosis of gout; 2 ) base case definition requiring $\geq 1$ visit in any care setting with a primary ICD-10 diagnosis of gout; and 3) strict case definition requiring $\geq 2$ visits with a primary ICD-10 diagnosis of gout in any care setting or $\geq 1$ diagnosis of gout at a visit to a rheumatologist. The latter definition has been shown in our previous validation study to have a positive predictive value in relation to the Mexico and Netherlands classification criteria for gout of $\geq 80 \%$ in Sweden [20].

\section{Definitions of comorbidities and ULT treatment}

Common comorbidities were separately identified for prevalent cases by 31 December 2012 for those fulfilling the three case definitions for gout. Comorbidities were defined as the presence of at least one visit to a physician in primary or specialized care or a hospitalization with a corresponding ICD-coded diagnosis during 20022012 (for ICD-10 codes see Additional file 1: Table S1). The treatment with diuretics was defined as having at least one dispensed prescription during 2012 (for ATC codes see Additional file 1: Table S1).

ULT treatment during 2012 was defined in a similar fashion as having at least one dispensed prescription for any of the following drugs in 2012: allopurinol, febuxostat, and probenecid (for ATC codes see Additional file 1: Table S1).

Using the information from 2012 regarding those treated with ULT, we also calculated the prevalence that year for people fulfilling any of our three definitions for gout and having a dispensed prescription of ULT in 2012.

\section{Definitions of rural and urban municipality}

Eighty-five percent of the Swedish population is living in urban conditions defined as a community with more than 200 inhabitants and a distance shorter than 200 meters between houses [21]. WSHCR consists of 49 municipalities with populations ranging from 4665 to 526,089. In nine of the 49 municipalities in WSHCR, $\geq 85 \%$ of the population live in an urban environment and, in the remaining 40 municipalities, $\leq 81 \%$ of the population live in an urban environment [21] (for more information see Additional file 2: Figure S1).

\section{Statistical analysis}

Prevalence was calculated using the number of people aged 20 years and above fulfilling our case definitions for gout (liberal, base, strict), overall and with ULT treatment, who were alive and living in WSHCR by 31 December 2012 as the numerator and the total population aged 20 years and above in WSHCR by 31 December 2012 as the denominator.

Incidence was calculated using the number of incident gout cases aged 20 years and above per calendar year as the numerator and the total person-years occurring in the population aged 20 years and above in WSHCR at the same year as the denominator. The incidence of gout in 2012 was defined as the number of patients that received a primary or auxiliary diagnosis of gout in 2012, 
the liberal case definition, with no recorded diagnosis of gout in the preceding 10 years (2002-2011). When defining incidence for analyses of trends we arbitrarily defined an incident case as a patient not having had a visit with a recorded primary or auxiliary (liberal case definition) diagnosis of gout during the preceding 3 calendar years in order to ensure comparability between the different years; thus, this was analysis of trends performed between 2005 and 2012. A sensitivity analysis requiring a 5-year period free of gout diagnosis, analyzing trends in incidence for the period 2007-2012, was also performed.

Descriptive statistics were used to summarize the demographic characteristics. We calculated both crude and standardized estimates (direct method) using the whole Swedish population aged $\geq 20$ years in 2012 as the standard population when comparing the prevalence in rural and urban municipalities and when comparing incidence rates by year in the analyses of trends. The significance of linear incidence trend was performed using logistic regression models. All statistical analyses were performed using SAS 9.4.

\section{Results}

\section{Prevalence and ULT treatment}

We identified 30,430 individuals aged 20 years and above with $\geq 1$ ICD-10 diagnosis (primary or auxiliary) of gout in WSHCR from 1 January 2002 to 31 December 2012. Out of these, 8007 individuals had either emigrated or died by the end of 2012, leaving a total of 22,423 living individuals in the area in 2012 (for more information and flowchart see Additional file 2: Figure S1). This corresponds to crude point prevalence in 2012 according to the liberal, base, and strict definitions for gout of $1.8 \%, 1.4 \%$, and $0.5 \%$, respectively (Fig. 1).
ULT was only dispensed to a minority of the gout patients in 2012, with a period prevalence of $42 \%, 37 \%$, and $55 \%$ for patients fulfilling the liberal, base, and strict case definitions (Fig. 1). The vast majority was prescribed allopurinol, less than $2 \%$ received probenecid, and febuxostat was not used at all in 2012.

The characteristics of gout cases, whether using the liberal, base, or strict definition, were similar overall (Table 1). There was a male predominance (range 70 $79 \%)$ and the mean age was 68-69 years. There were high frequencies of comorbidities known to be associated with gout (Table 1) that were similar irrespective of gout case definition, with approximately $63-68 \%$ of the cases having a previous diagnosis of hypertension, 25$27 \%$ of ischemic heart disease, $13-14 \%$ of stroke, 20 $23 \%$ of diabetes mellitus, $17-20 \%$ of renal disease, and $20-21 \%$ having concurrent medication with thiazide diuretics (Table 1).

The prevalence of gout in WSHCR was higher in men and increased with age, with a prevalence of more than $3 \%$ in men aged $50-59$ years and almost $7 \%$ in men aged 70-79 years (Fig. 2). The sex difference in prevalence was most pronounced in those aged 30 to 59 years, with a male to female ratio of $3: 1$ to $4: 1$, which decreased to a two-fold increase in patients above 70 years (Fig. 2).

\section{Prevalence in urban and rural areas}

The age- and gender-standardized [18] prevalence of gout was slightly higher in the municipalities with more rural milieu $(1.73 \%)$ compared to the ones with a more urban environment $(1.67 \%)$, although this difference was not significant (for map illustrating the geographical location see Additional file 3: Figure S2).

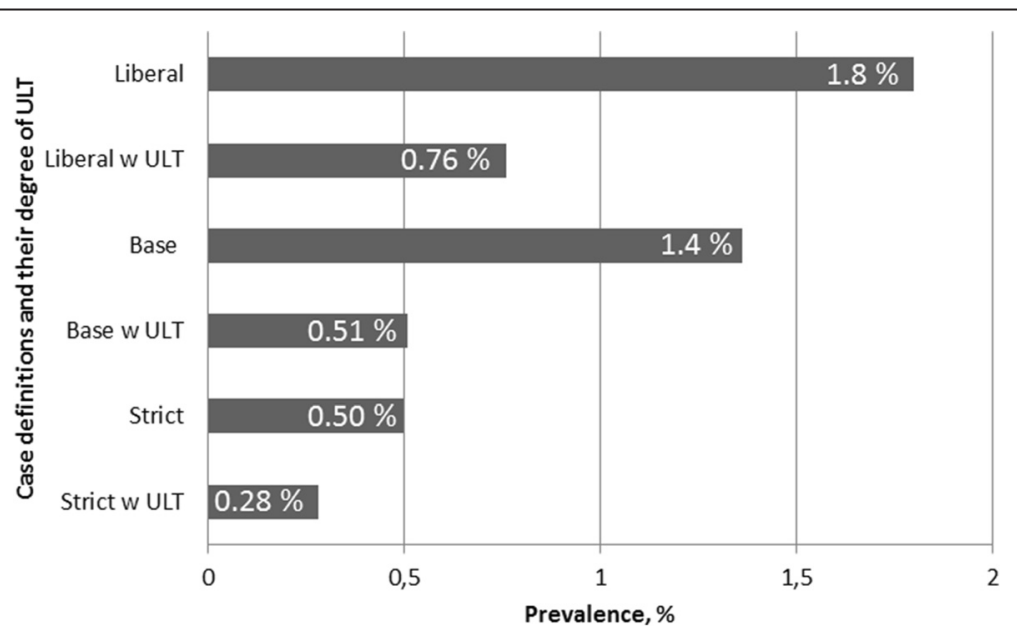

Fig. 1 Prevalence of gout in WSHCR at 31 December 2012 in people aged $\geq 20$ years by different case definitions and degree of urate-lowering treatment (ULT). W With 
Table 1 Prevalence of gout according to the liberal, base, and strict case definitions with patient characteristics for the three groups

\begin{tabular}{|c|c|c|c|}
\hline & Liberal case definition $n=22,243$ & Base case definition $n=16,833$ & Strict case definition $n=6184$ \\
\hline Total population & $1,237,935$ & & \\
\hline Total prevalence $(95 \% \mathrm{Cl})$ & $1.8(1.77-1.82)$ & $1.36(1.34-1.38)$ & $0.5(0.49-0.51)$ \\
\hline Sex (male), \% & $70 \%$ & $72 \%$ & $79 \%$ \\
\hline Age 2012 (years), mean (SD) & $69(14)$ & $68(14)$ & $68(14)$ \\
\hline \multicolumn{4}{|l|}{ Level of education ${ }^{a}$} \\
\hline 9 years or less & $47 \%$ & $45 \%$ & $45 \%$ \\
\hline 9 to 12 years & $38 \%$ & $39 \%$ & $40 \%$ \\
\hline More than 12 years & $15 \%$ & $16 \%$ & $15 \%$ \\
\hline \multicolumn{4}{|l|}{ Co-morbidities } \\
\hline Hypertension & $68 \%$ & $63 \%$ & $67 \%$ \\
\hline Diabetes & $23 \%$ & $20 \%$ & $21 \%$ \\
\hline Ischemic heart disease & $27 \%$ & $25 \%$ & $28 \%$ \\
\hline Congestive heart failure & $20 \%$ & $18 \%$ & $22 \%$ \\
\hline Stroke & $14 \%$ & $13 \%$ & $14 \%$ \\
\hline Renal disease & $19 \%$ & $17 \%$ & $20 \%$ \\
\hline \multicolumn{4}{|l|}{ Diuretic treatment } \\
\hline Thiazide & $21 \%$ & $20 \%$ & $20 \%$ \\
\hline Loop & $41 \%$ & $37 \%$ & $37 \%$ \\
\hline Potassium conserving diuretics & $22 \%$ & $20 \%$ & $20 \%$ \\
\hline
\end{tabular}

${ }^{a} 4 \%$ missing data on level of education in the liberal case definitions and $2 \%$ missing in base and strict case definition

$\mathrm{Cl}$ confidence interval, SD standard deviation

\section{Incidence}

The incidence of gout in 2012, demanding 10 preceding years (2002-2011) with no recorded diagnosis of gout, was 190 cases per 100,000 person-years (Table 2). The male to female ratio was more than $3: 1$ in those aged below 70 years, whereas it was only $2: 1$ to $3: 1$ in those aged above 70 years (Table 2).

The incidence of gout increased steadily and significantly from 2005 to 2012, with an almost $50 \%$ increase in the total population ( $p=0.0014$; Fig. 3$)$. The male to female ratio of gout incidence was consistently higher than 2:1 for all the years 2005 to 2012 (Fig. 3). In a sensitivity analysis, we also calculated incidence trend with a requirement of 5 preceding years without gout

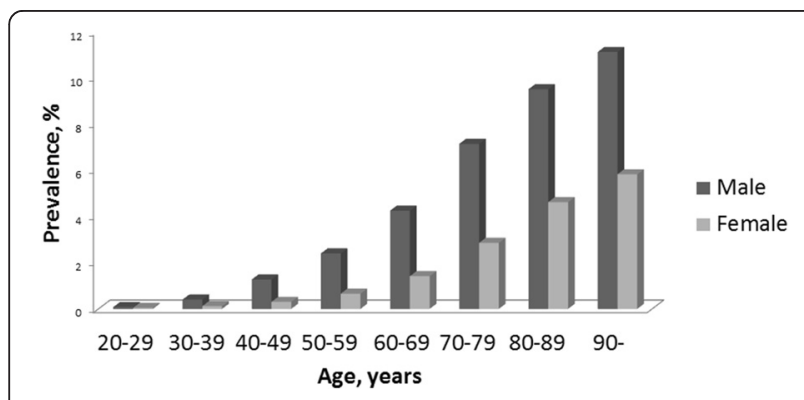

Fig. 2 Prevalence of gout in WSHCR at 31 December 2012 in people age $\geq 20$ years by age and sex according to the liberal case definition diagnosis, which resulted in similar results with a significant increase in incidence from 2007 to $2012(p=0.019)$.

\section{Discussion}

In the present study we found an overall prevalence of ever-diagnosed gout in WSHCR Sweden in 2012 of $1.8 \%$, and $0.5 \%$ when using a more stringent definition for disease. The incidence in 2012 was 190 per 100,000 person-years, with a significant increase over the previous decade. There was no significant difference in prevalence between urban and rural areas. In 2012, only a minority of the patients were treated with ULT.

The occurrence of gout has only scarcely been reported from Sweden and the neighboring Nordic countries $[12-15,22]$. Studies from the rest of Europe have reported a variation in prevalence, with $2.5 \%$ being reported in the UK for 2012 [1], 1.4 \% in Germany for 2000 through 2005 [23], $0.9 \%$ in France for 2013 [5, 8], and $0.9 \%$ in Italy for 2009 [16]. Differences between studies may reflect different case ascertainment or true variation, possibly related to cultural and genetic differences between populations. In the present study we also applied a more strict method for defining gout, requiring two visits with a gout diagnosis in any care setting or one visit with such a diagnosis to a rheumatologist, by which we only identified approximately $25 \%$ of the cases identified with the liberal definition. The strict definition 
Table 2 Incidence of gout in the Western Swedish Health Care Region in 2012 age $\geq 20$ years per 100,000 person-years with 95 \% confidence intervals overall, and by sex and by age groups

\begin{tabular}{lllll}
\hline Group & Male & & \multicolumn{2}{l}{ Female } \\
\cline { 2 - 4 } & $n$ & Incidence rate $(95 \% \mathrm{Cl})$ & 747 & $116(110-130)$ \\
\hline Overall & 1639 & $267(260-280)$ & 9 & $8(0-20)$ \\
$20-29$ years & 20 & $18(10-30)$ & 16 & $16(10-30)$ \\
$30-39$ years & 74 & $71(60-90)$ & 51 & $47(40-60)$ \\
$40-49$ years & 177 & $158(140-180)$ & 76 & $78(60-100)$ \\
$50-59$ years & 273 & $277(250-310)$ & 145 & $151(130-180)$ \\
$60-69$ years & 438 & $457(420-500)$ & 190 & $302(260-350)$ \\
$70-79$ years & 370 & $654(590-720)$ & 196 & $346(300-400)$ \\
$80-89$ years & 235 & $865(760-980)$ & 64 & $598(470-760)$ \\
90 years and above & 52 & $1168(890-1530)$ &
\end{tabular}

$\mathrm{Cl}$ confidence interval

has previously been validated by us and has been shown to have a positive predictive value for fulfilling classification criteria for gout of over $80 \%$, which was considerably higher compared to the positive predictive value for gout according to our liberal definition [20]. This reflects more frequent visits to the healthcare system with a diagnosis of gout by those defined by the strict definition and is likely to mirror a more severe disease phenotype. Although this supports the validity of our strict definition, it should be emphasized that classification criteria are intended to be used for classification in research studies and not for individual clinical diagnosis. This holds true not least for the 1977 ARA criteria for gout $[24,25]$. The group defined according to the strict definition exhibited similar patterns of comorbidities and educational level as those defined according to the liberal or base definitions, but received ULT to a greater extent. This is compatible with the view that our liberal definition indeed represents true gout, but also that those defined according to the strict definition represent a more severe phenotype. Differences in ULT between

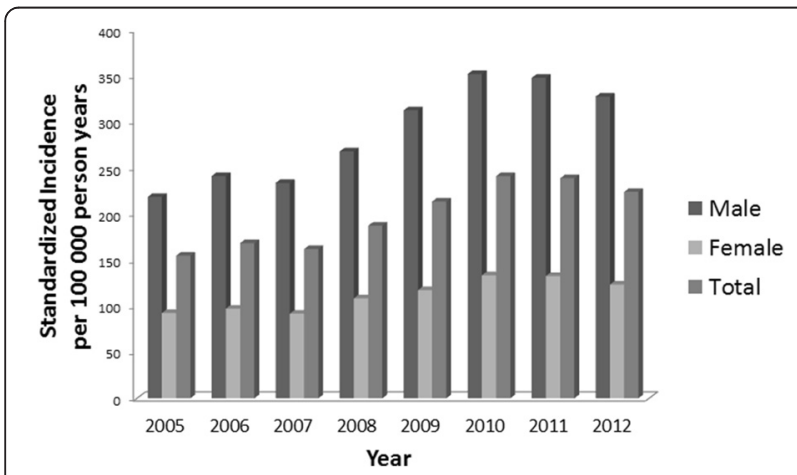

Fig. 3 Incidence of gout in WSHCR 2005-2012 in people aged $\geq 20$ years in total and by sex per 100,000 person-years, standardized for age and sex using the Swedish population as standard the liberal and strict group may reflect that insufficient gout treatment is more pronounced in those with less severe disease. The three case definitions represent three levels of diagnostic certainty. A higher level of diagnostic certainty (as used in our strict definition) is mandatory when causal relationships or etiology to disease should be investigated. Although having high specificity, such a definition may have low sensitivity for detecting the whole spectrum of disease, a problem we addressed by also using a liberal definition for gout. Since several recent studies on rheumatoid arthritis from Sweden have only reported prevalence figures of $0.7 \%$, our findings indicate that gout is the most common form of arthritis in Sweden [26, 27].

Few studies have addressed the incidence of gout in the world, and there are no contemporary studies from Sweden and the Nordic countries. A Finnish study from 1974 reported 12 cases per 100,000 person-years with no incident cases in women [22]. In our study, the incidence of gout in women was 116 per 100,000 personyears. Surprisingly, we identified 76 women aged 20-49 years, thus possibly premenopausal, with incident gout, which is similar to results in the UK in 2012 [1]. Considering the conception that gout is very rare in people of this age, these cases would have benefited from specific validation, which was not possible as part of this register study. The gout incidence in 2012 of 190 per 100,000 person-years in our study was also similar to that reported in the UK [1], but was about twice as high as that reported from Italy [23]. We found an almost $50 \%$ increase in the incidence of gout from 2005 to 2012, results which are similar to those reported in the UK [1]. This probably reflects a true increase of the disease in Sweden, although it may also be partly influenced by changes in diagnostic recording routines over time.

Geographical variation in the prevalence of gout has been reported from the UK [1] and Italy [16]. In the UK 
study, the differences were suggested to be related to differences in socioeconomic status, lifestyle, and nutrition. A north-south prevalence gradient was observed in the Italian study, and was suggested to be attributed to different dietary habits related to the Mediterranean diet. In our study, we found a no difference in prevalence in rural compared to more urban municipalities. Older studies from the UK and Finland have, on the other hand, reported a higher risk in urban areas compared to rural ones [14, 28].

Thirty-seven to $55 \%$ of the gout patients in the study were on ULT treatment in 2012, using the base and strict case definition, respectively. These figures are low, especially considering the growing number of recommendations to treat gout with ULT earlier in the disease course. Studies from the UK [1] and Taiwan [29] confirm that this is a widespread problem, although it is unclear how large the proportion of patients with gout is that ideally should be treated. Further studies are needed to explore to what extent these low figures are due to poor compliance by patients or to shortcomings of the healthcare system.

There are several possible limitations of our study. First, our case definitions were based on diagnoses of gout made in the clinical situation rather than according to the different proposed classification criteria [30-35], which may have led to misclassification bias. We have, however, previously validated our strict case definition [20] and found it to have a high predictive value for fulfilling classification criteria for gout. In addition to this definition, we chose to report on ever-diagnosed gout, the liberal case definition, to increase comparability to previous studies. Second, gout has an intermittent course with possibly long clinically silent phases which may hamper any attempt to find the true occurrence of the disease, a problem that may be of less importance in the present study since we had a long observation period. Furthermore, sensitivity analyses using different assumptions in the analyses of incidence trends resulted in similar estimates supporting the robustness of our results. Third, the study was performed in the western part of Sweden which may not be nationally representative. However, other studies have demonstrated very similar statistics with regard to sociodemographic distribution and healthcare seeking in this region compared to Sweden as a whole $[17,18]$.

There are also several strengths of the present study. First, using the healthcare registers in the Swedish setting with virtually complete coverage makes the results population representative. Second, loss to follow-up is a minor problem since death or emigration are reliably followed in this population by the central statistics in Sweden. Third, the estimates for ULT were retrieved from an independent data source.

\section{Conclusion}

In conclusion, we found an increasing incidence of gout over the last decade with a prevalence in WSHCR of $1.8 \%$ in 2012. According to a more stringent definition, probably reflecting a more severe phenotype, only $0.5 \%$ had gout. Irrespective of definition, management of gout measured by the degree of ULT in 2012 was as poor as that reported in other European countries previously.

\section{Additional files}

Additional file 1: Table S1. Definition of co-morbidities by ICD-10 codes and ULT and diuretics by ATC codes. (DOCX 93 kb)

Additional file 2: Figure S1. Flowchart of gout patients who were identified, migrated, and died. (TIF $379 \mathrm{~kb}$ )

Additional file 3: Figure S2. Map of WSHCR with municipalities with $\geq 85 \%$ of their population living in urban environment (dark grey) and the municipalities with $\leq 81 \%$ of their population living in urban environment (light grey). (TIF $284 \mathrm{~kb}$ )

\section{Abbreviations}

ATC, Anatomical Therapeutic Chemical Classification System; Cl, confidence interval; ICD, International Classification of Diseases; ULT, urate-lowering treatment; VEGA, Western Swedish Health Care Register; WSHCR, Western Swedish Health Care Region

\section{Funding}

Funding for the study was received from the following sources, which did not influence either the design of the study, the collection and analysis of the data, or the preparation of the manuscript: Reumatikerfonden, the Felix Neubergh Foundation, the Inger Bendix Foundation for Medical Research, the Hjalmar Svenssons Research Fund, the Amlöv Foundation for Rheumatological Research and Gothenburg University. All researchers assigned as authors state their complete independence from the funders with regard to this study.

\section{Authors' contributions}

All authors have contributed substantially in the process of completing this study and had full access to the data, specified as follows: MD contributed to the conception and design of the study, as well as managing and interpretation of data, and drafting and revising the manuscript. PD, VS, and AS contributed to design, interpretation of data, drafting and revising the manuscript. LTHJ contributed to the conception and design of the study, as well as interpretation of data, and drafting and revising the manuscript. All authors have approved the manuscript and agree to be accountable.

\section{Competing interests}

The authors declare that they have no competing interests.

\section{Ethical approval and consent to participate}

Ethical approval for the study was granted from the Ethical Review Board of Gothenburg, Sweden. Patient consent was waived, as data were derived from administrative registers that do not require such consent.

\section{Author details}

'Department of Rheumatology and Inflammation Research, Institute of Medicine, Sahlgrenska Academy, University of Gothenburg, Gothenburg, Sweden. ${ }^{2}$ Rheumatology Clinic, Falun Hospital, Falun, Sweden.

Received: 12 April 2016 Accepted: 24 June 2016

Published online: 13 July 2016

\section{References}

1. Kuo CF, Grainge MJ, Mallen C, Zhang W, Doherty M. Rising burden of gout in the UK but continuing suboptimal management: a nationwide population study. Ann Rheum Dis. 2015;74(4):661-7. 
2. Zhu Y, Pandya BJ, Choi HK. Prevalence of gout and hyperuricemia in the US general population: the National Health and Nutrition Examination Survey 2007-2008. Arthritis Rheum. 2011;63(10):3136-41.

3. Smith E, Hoy D, Cross M, Merriman TR, Vos T, Buchbinder R, Woolf A, March $L$. The global burden of gout: estimates from the Global Burden of Disease 2010 study. Ann Rheum Dis. 2014;73(8):1470-6.

4. Roddy E, Choi HK. Epidemiology of gout. Rheum Dis Clin North Am. 2014;40(2):155-75.

5. Bardin T, Bouee S, Clerson P, Chales G, Flipo RM, Liote F, Perez V, Poiraud T, Schaeverbeke T, Richette P. Prevalence of gout in the adult population of France. Arthritis Care Res. 2016;68(2):261-6.

6. Roddy E, Doherty M. Epidemiology of gout. Arthritis Res Ther. 2010;12(6):223.

7. Meier $\mathrm{CR}$, Jick H. Omeprazole, other antiulcer drugs and newly diagnosed gout. Br J Clin Pharmacol. 1997;44(2):175-8.

8. Richette P, Clerson P, Bouee S, Chales G, Doherty M, Flipo RM, Lambert C, Liote F, Poiraud T, Schaeverbeke T et al. Identification of patients with gout: elaboration of a questionnaire for epidemiological studies. Ann Rheum Dis. 2015;74(9):1684-90.

9. Choi HK, Curhan G. Independent impact of gout on mortality and risk for coronary heart disease. Circulation. 2007;116(8):894-900.

10. Krishnan E, Svendsen K, Neaton JD, Grandits G, Kuller LH, Group MR. Long-term cardiovascular mortality among middle-aged men with gout. Arch Intern Med. 2008;168(10):1104-10.

11. Kuo CF, Grainge MJ, Zhang W, Doherty M. Global epidemiology of gout: prevalence, incidence and risk factors. Nat Rev Rheumatol. 2015;11(11):649-62.

12. De Muckadell OB, Gyntelberg F. Occurrence of gout in Copenhagen males aged 40-59. Int J Epidemiol. 1976;5(2):153-8.

13. Bergstrom G, Bjelle A, Sorensen LB, Sundh V, Svanborg A. Prevalence of rheumatoid arthritis, osteoarthritis, chondrocalcinosis and gouty arthritis at age 79. J Rheumatol. 1986;13(3):527-34.

14. Isomaki HA. Prevalence and social impact of rheumatic diseases in Finland. J Rheumatol Suppl. 1983;10:29-33.

15. Wandell P, Carlsson AC, Ljunggren G. Gout and its comorbidities in the total population of Stockholm. Prev Med. 2015;81:387-91.

16. Trifiro G, Morabito P, Cavagna L, Ferrajolo C, Pecchioli S, Simonetti M, Bianchini E, Medea G, Cricelli C, Caputi AP et al. Epidemiology of gout and hyperuricaemia in Italy during the years 2005-2009: a nationwide population-based study. Ann Rheum Dis. 2013;72(5):694-700.

17. Ministry of Health and Social Affairs SGO. Updated high-cost protection-outpatient care and medication. 2013. ISBN 978-91-7555-111-1.

18. Statistiska C. Folkmängden efter region, civilstånd, ålder och kön. År 19682014 www.scb.se. 2012.

19. Socialstyrelsen: Läkemedelsregistret http://www.socialstyrelsen.se/register/ halsodataregister/lakemedelsregistret.

20. Dehlin M, Stasinopoulou K, Jacobsson L. Validity of gout diagnosis in Swedish primary and secondary care-a validation study. BMC Musculoskelet Disord. 2015;16:149.

21. Götalandsregionen AV. Tätortsboende Västra Götaland 2005 och 2010. 2010. http://www.vgregion.se/upload/Regionkanslierna/regionutveckling/Statistik/ statkarta/wizlets/Tatortsboende.html.

22. Isomaki H, Raunio J, von Essen R, Hameenkorpi R. Incidence of inflammatory rheumatic diseases in Finland. Scand J Rheumatol. 1978;7(3):188-92.

23. Annemans L, Spaepen E, Gaskin M, Bonnemaire M, Malier V, Gilbert T, Nuki G. Gout in the UK and Germany: prevalence, comorbidities and management in general practice 2000-2005. Ann Rheum Dis. 2008;67(7):960-6.

24. Malik A, Schumacher HR, Dinnella JE, Clayburne GM. Clinical diagnostic criteria for gout: comparison with the gold standard of synovial fluid crystal analysis. J Clin Rheumatol. 2009;15(1):22-4.

25. Janssens $H J$, Janssen $M$, van de Lisdonk EH, Fransen J, van Riel PL, van Weel C. Limited validity of the American College of Rheumatology criteria for classifying patients with gout in primary care. Ann Rheum Dis. 2010;69(6):1255-6.

26. Englund M, Joud A, Geborek P, Felson DT, Jacobsson LT, Petersson IF. Prevalence and incidence of rheumatoid arthritis in southern Sweden 2008 and their relation to prescribed biologics. Rheumatology. 2010;49(8):1563-9.

27. Neovius M, Simard JF, Askling J, ARTIS Study Group. Nationwide prevalence of rheumatoid arthritis and penetration of disease-modifying drugs in Sweden. Ann Rheum Dis. 2011:70(4):624-9.
28. Currie WJ. Prevalence and incidence of the diagnosis of gout in Great Britain. Ann Rheum Dis. 1979:38(2):101-6.

29. Kuo CF, Grainge MJ, See LC, Yu KH, Luo SF, Zhang W, Doherty M. Epidemiology and management of gout in Taiwan: a nationwide population study. Arthritis Res Ther. 2015;17:13.

30. Kellgren JHJM, Ball JF. The epidomiology of chronic rheumatism. Oxford: Blackwell Scientific; 1963.

31. Decker J. Report from the subcommittee on diagnostic criteria for gout. In: Bennett PH, Wood PHN, editors. Population studies of the rheumatic diseases. Proceedings of the Third International Symposium, New York, June 5-10, 1966. Amsterdam: Excerpta Medica Foundation; 1968. p. 385-7.

32. Wallace SL, Robinson H, Masi AT, Decker JL, McCarty DJ, Yu TF. Preliminary criteria for the classification of the acute arthritis of primary gout. Arthritis Rheum. 1977;20(3):895-900.

33. Pelaez-Ballestas I, Hernandez Cuevas C, Burgos-Vargas R, Hernandez Roque L, Teran L, Espinoza J, Esquivel-Valerio JA, Goycochea-Robles MV, Aceves FJ, Bernard AG et al. Diagnosis of chronic gout: evaluating the American College of Rheumatology proposal, European League against Rheumatism recommendations, and clinical judgment. J Rheumatol. 2010;37(8):1743-8.

34. Janssens HJ, Fransen J, van de Lisdonk EH, van Riel PL, van Weel $C_{1}$, Janssen M. A diagnostic rule for acute gouty arthritis in primary care without joint fluid analysis. Arch Intern Med. 2010;170(13):1120-6.

35. Neogi T, Jansen TL, Dalbeth N, Fransen J, Schumacher HR, Berendsen D, Brown M, Choi H, Edwards NL, Janssens HJ et al. 2015 Gout classification criteria: an American College of Rheumatology/European League Against Rheumatism collaborative initiative. Ann Rheum Dis. 2015:74(10):1789-98.

\section{Submit your next manuscript to BioMed Central and we will help you at every step:}

- We accept pre-submission inquiries

- Our selector tool helps you to find the most relevant journal

- We provide round the clock customer support

- Convenient online submission

- Thorough peer review

- Inclusion in PubMed and all major indexing services

- Maximum visibility for your research

Submit your manuscript at www.biomedcentral.com/submit
) Biomed Central 